\title{
Trace element mapping in pyrite framboids by atom probe tomography
} N.M. ATIENZA1 ${ }^{*}$, D.D. GREGORY1, S.D. TAYLOR2,
D.E. PEREA2, J.D. OWENS 3 AND T.W. LYONS 4

1Department of Earth Sciences, University of Toronto, ON

Canada (*nicole.atienza@utoronto.ca)

2Environmental Molecular Sciences Laboratory, Pacific

Northwest National Laboratory, Richland, WA USA

3Florida State University, National High Magnetic Field

Laboratory, Tallahassee, FL USA

4Department of Earth and Planetary Sciences, University of

California, Riverside, CA USA

Ancient ocean chemistry can be tracked by analyzing trace element content in bulk sediments and minerals [1]. However, the mechanism by which these trace elements are held can affect our interpretation of the signals. In this contribution, we are investigating trace element signatures in pyrite to refine the utility of the pyrite proxy.

Pyrite framboids analyzed in this study were taken from three sites: modern Cariaco Basin (Carribean Sea), Cretaceous Demerara Rise (western equatorial Atlantic), and Devonian Leicester Pyrite Member (outcrop from Fall Brook, New York). The geochemistries of these sites are relatively well understood based on past studies of local and global redox conditions. By selecting samples from sites that are well known and have been exposed to limited metamorphism, we can better differentiate between features in ancient pyrite that are primary versus those that are likely products of secondary remobilization.

LA-ICP-MS is commonly used to determine how trace elements are incorporated into pyrite [2]. However, the limited spatial resolution of time-resolved, laser ablation output graphs precludes the ability to accurately determine their distributions (i.e., lattice or evenly distributed as nanoinclusions). In this study, atom probe tomography (APT) was used to map the 3D location of trace elements in framboidal pyrite. The APT revealed zones of high concentration of elements at grain boundaries or different possible phases of pyrite. Differentiating multiple generations of pyrite formation and furthering the knowledge on trace element incorporation is essential as we seek to accurately determine changing conditions in the Earth's oceans and atmosphere.

[1] Large et al. (2014) Earth and Planetary Science Letters 389, 209-220. [2] Gregory et al. (2015) Economic Geology 110, 1389-1410. 